\title{
Potential risks and solutions for sharing genome summary data from African populations
}

\author{
Nicki Tiffin ${ }^{1,2,3}$ (D)
}

\begin{abstract}
Genome data from African population can substantially assist the global effort to identify aetiological genetic variants, but open access to aggregated genomic data from these populations poses some significant risks of community- and population- level harms. A recent amendment to National Institutes of Health policy, following various engagements with predominantly North American scientists, requires that genomic summary results must be made available openly on the internet without access oversight or controls.

The policy does recognise that some sensitive, identifiable population groups might be harmed by such exposure of their data, and allows for exemption in these cases. African populations have a very wide and complex genomic landscape, and because of this diversity, individual African populations may be uniquely re-identified by their genomic profiles and genome summary data. Given this identifiability, combined with additional vulnerabilities such as poor access to health care, socioeconomic challenges and the risk of ethnic discrimination, it would be prudent for the National Institutes of Health to recognise the potential of their current policy for community harms to Africans; and to exempt all African populations as sensitive or vulnerable populations with regard to the unregulated exposure of their genome summary data online.

Three risk-mitigating mechanisms for sharing genome summary results from African populations to inform global genomic health research are proposed here; namely use of the Beacon Protocol developed by the Global Alliance for Genomics and Health, user access control through the planned African Genome Variation Database, and regional aggregation of population data to protect individual African populations from re-identification and associated harms.
\end{abstract}

Keywords: African genomes, Genome summary results, African diversity, Community harms

\section{Background}

Because of the complexity and depth of African genomes compared to rest-of-world populations, genome summary data that include population allele frequencies from African populations can greatly enhance identification of disease-causing and other variants in African as well as rest-of-world research, and advances in health genomics research on the African Continent can contribute meaningfully to biomedical research globally [1].

\footnotetext{
Correspondence: nicki.tiffin@uct.ac.za

${ }^{1}$ Computational Biology Division, Integrative Biomedical Sciences, University of Cape Town, Cape Town, South Africa

${ }^{2}$ Wellcome Centre for Infectious Disease Research in Africa, Institute of Infectious Diseases and Molecular Medicine, University of Cape Town, Cape Town, South Africa

Full list of author information is available at the end of the article
}

Since 2008, genomic summary results (GSR) had been archived in controlled-access portions of NIH-designated data repositories due to concerns that an individual's inclusion in a group could be ascertained given their whole genome data [2]. In November 2018, the National Institutes of Health $(\mathrm{NIH})$ released a statement updating their policy on management of access to GSR, based on recent workshops and various engagement mechanisms undertaken in the USA to explore access options for sharing GSR.

The NIH concluded that respondents in general believed that benefits of open access to GSR outweigh the risks. This informed the subsequent NIH requirement that GSR generated with NIH funding should be made freely available on the internet with no access restriction - with the caveat that some sensitive population groups

(c) The Author(s). 2019 Open Access This article is distributed under the terms of the Creative Commons Attribution 4.0 International License (http://creativecommons.org/licenses/by/4.0/), which permits unrestricted use, distribution, and reproduction in any medium, provided you give appropriate credit to the original author(s) and the source, provide a link to the Creative Commons license, and indicate if changes were made. The Creative Commons Public Domain Dedication waiver (http://creativecommons.org/publicdomain/zero/1.0/) applies to the data made available in this article, unless otherwise stated. 
could be exempt from this requirement due to a risk of stigmatisation of specific communities or populations. This amended policy also applies to research programs in Africa that are funded by the $\mathrm{NIH}$, and it is important to review how the policy might affect the protection of African study participants and their communities, particularly as it appears that there was no documented engagement with African stakeholders when considering the amendment of the policy.

According to documented elements of the public engagement process, the NHGRI Workshop on Aggregate Genomic Data (May 2016), had predominantly North American attendees and no registered African representatives [3]. A "Request for Information" call in 2017 [4] recorded responses from 109 parties (37 of whom appeared to be users of ExAC and gnomAD databases who were solicited to respond using standardised text), of whom $79 \%$ were scientific researchers [5] and none were African [6]. Finally, the GSR access policy was discussed at a Genomic Variation Program Workshop on Establishing a Central Resource of Data from Genome Sequencing Projects (June 2012) [7], which also had no African representation in speakers or scheduled content, although the participant list of this workshop is not available to confirm whether Africans were present.

\section{Main text}

It is, however, important to consider the genomic depth and breadth of African genomes and the consequent ability to genetically distinguish small populations and communities from each other, often in approximation of ethnicity or ancestral lineage $[8,9]$. This inherent genomic complexity of African populations is often disregarded in Caucasiancentric policies and recommendations, and community or population-level risks may be overlooked because such reidentification of specific Caucasian communities using genomic data is unlikely. Current National boundaries in Africa were arbitrarily defined during colonisation, and multiple African populations may co-exist in a single Nation, which in some cases has resulted in tensions between different population groups.

The ability to fine-map population-level genomic data to specific communities comes with inherent community-level risks that have already been experienced by minority Indigenous populations on other continents - such as the experiences of the Havasupai Native Americans [10, 11], or the negative implications of genomic research for the San population in Southern Africa [12, 13]. History is littered with examples of opaque, invasive, and often poor quality research that has damaged vulnerable communities [14]; such as the Xavante and Yanomani populations in Brazil [15, 16], or the Indigenous populations of Australia and New Zealand [17, 18].
It is notable that three of the respondents to the $\mathrm{NIH}$ "Request for Information" were representing Native American Tribes, namely the Sault Ste. Marie Tribe of Chippewa Indians (submitted by Larry Jacques), the Southcentral Foundation (submitted by Denise A Dillard), and United South and Eastern Tribes Sovereignty Protection Fund (submitted by Liz Malerba). These commentaries all included strong recommendations that any genomic information should be reviewed by Tribal review boards and/or community representatives before release. Concerns were expressed that unlimited and indefinite use of genomic summary data without oversight is dangerous to the ongoing trust relationship between Tribal populations and the NIH; that ongoing and future determination of harms from genomic information collected from tribal populations must be facilitated; and that NIH program officers and scientific reviewers might push widespread data sharing in direct contradiction to tribes' requirements as sovereign nations [6].

As with Indigenous populations in North America and Australasia, as well as other sensitive populations across the globe, full genomic summary data for identifiable African populations or communities published online without any oversight could expose these people to a high risk of discrimination or stigmatisation. As further variant-phenotype associations are discovered, allele frequencies for these variants can be assayed in different populations using GSR, and predictions made about trait prevalence in those populations. The genomic diversity and distance between different African populations is sufficiently large, even on a local scale, that genomic summary data can uniquely identify individual communities $[8,9]$ who can be geographically located, and associated phenotypes can be ascribed to those specific communities based on their aggregated allele frequencies. Given known examples of ethnic discrimination, violence and xenophobia within Africa [19], as well as unfortunate historical and ongoing misappropriation of genetic data to publicly denigrate African populations $[20,21]$, the open availability of summary genome data for distinct African ethnic groups may be unethical because of the untenable risk of harms accruing to those populations. As such, African populations should all be regarded as 'special populations' for the purposes of the new NIH policy to ensure they are protected from such harms, in line with conclusions drawn in that policy that privacy risks related to broad access to GSR may be heightened for some study populations. Furthermore, participants who have provided DNA samples to date are unlikely to have consented to have their data shared openly without Access Committee oversight; and specific consent for aggregate data sharing - with full participant information about potential harms - is needed from individuals as well as generally accepted representative 
community organisations before further sharing of these aggregated data.

Here, we propose a framework for the use of GSR from African populations that could greatly reduce the risk to African participants, whilst still facilitating the general use of African summary genomic data to inform and advance global research to identify aetiological variants and contribute to advancing health research. This framework has three components that provide options for appropriate levels of summary data use.

\section{Use of GA4GH beacons}

In this use case, a researcher seeking to prioritise candidate disease-causing variants in another population could check whether candidate variants have been identified in African populations, if so, at what frequency, and/or whether they have been associated with a specific disease in African populations. The Global Alliance for Genomics and Health (GA4GH) Beacon protocol $[22,23]$ allows researchers to make limited queries as to whether a particular variant has been seen in a particular dataset, thus encouraging sharing of information without compromising privacy, with proposed extensions to include queries of variant-phenotype associations through direct online access. Query rate limits can be used to restrict abuse of the system by "walking" across the genome using thousands of queries of the same aggregated dataset, but without restricting ease of access for honest research purposes.

\section{Registered user access through the African genome variation database}

The African Genome Variation Database (AGVD) is under development as a project of the H3Africa Informatics Network [24, 25], and aims to be a resource for exploring African variation data available to registered users. Regionally-aggregated genomic data summaries - for example for North, South, West and East Africa - can be made available for bona fide researchers who are reviewed as part the AGVD general administration for registered users. It is likely that such summaries will provide valuable allele frequency data for regional groupings without exposing communities or populations to potential harms; and that a genetic diversity metric such as Fst [26, 27] could determine an aggregation level that provides some granularity without exposing individual populations or communities.

\section{Access to study population pre-calculated genomic summary data through applications reviewed by an access committee}

Where requests for summary data cannot be met by the processes outlined above, applications for populationspecific summary data could be made through an appropriately constituted Access Committee, which should normally already be in place to administer access to individual-level genotype data where secondary data use consents are in place. It is likely that only in a small subset of cases would this detail review be required, as beacons and regional summaries should answer many of the use cases for external researchers. Should the number of requests become unmanageable for an existing access committee, a subcommittee could be constituted of individuals who are qualified to review specifically these requests under the oversight of the main committee. Where genotype data are submitted to central repositories such as the European Genome-Phenome Archive (EGA) [28], access to African genome summary data might be managed similarly to whole dataset requests in cases where Beacons or regional aggregated data do not suffice.

\section{Conclusions}

In conclusion, genome summary data from studies of African populations can substantially enhance ongoing health research in African and rest-of-world populations, and ethical and responsible sharing of these data should be supported. Open and unregulated online exposure of genome summary data from African populations or communities, however, may expose these populations to unacceptable risks and potential harms such as those experienced by Indigenous and/or minority population groups to date. Outlined here are three levels of controlled access to genome summary data from African populations and communities that can harness the benefits of these data for global and local health research, whilst mitigating the risks and potential harms for the African participants and communities who provide their samples and data for genomic research.

\section{Abbreviations}

AGVD: African Genome Variation Database; EGA: European GenomePhenome Archive; GA4GH: Genomic Alliance for Genomics and Health; GSR: Genome Summary Results; NIH: National Institutes of Health

\section{Acknowledgements}

The author acknowledges Nicola Mulder and Ayton Meintjes (Computational Biology Division, University of Cape Town) for review of proposed

technological solutions for protection of GSR online.

\section{Authors' contributions}

NT conceived of and wrote the manuscript. This author read and approved the final manuscript.

\section{Funding}

NT receives support from Wellcome (salary and research, 203135/Z/16/Z) and the National Institutes of Health (salary and research, H3ABioNet: R01HD080465 and salary, B-Positive: U24HG006941). The funding bodies played no role in the design of the study and collection, analysis, and interpretation of data and in writing the manuscript. The views expressed here are personal and not necessarily those of the funders.

Availability of data and materials

All information cited is openly available online and URLS are provided in the References section. 


\section{Ethics approval and consent to participate}

No ethics approval or consent was required for this work.

\section{Consent for publication}

No consent for publication was required for this work.

\section{Competing interests}

The authors declare that they have no competing interests.

\section{Author details}

${ }^{1}$ Computational Biology Division, Integrative Biomedical Sciences, University of Cape Town, Cape Town, South Africa. ${ }^{2}$ Wellcome Centre for Infectious Disease Research in Africa, Institute of Infectious Diseases and Molecular Medicine, University of Cape Town, Cape Town, South Africa. ${ }^{3}$ Centre for Infectious Disease Epidemiology Research, School of Public Health and Family Medicine, University of Cape Town, Cape Town, South Africa.

Received: 10 July 2019 Accepted: 16 October 2019

Published online: 04 November 2019

\section{References}

1. Rotimi CN, Bentley AR, Doumatey AP, Chen G, Shriner D, Adeyemo A. The genomic landscape of African populations in health and disease. Hum Mo Genet. 2017:26:R225-36.

2. Homer N, Szelinger S, Redman M, Duggan D, Tembe W, Muehling J, et al. Resolving individuals contributing trace amounts of DNA to highly complex mixtures using high-density SNP genotyping microarrays. PLoS Genet. 2008; 4:e1000167.

3. Workshop on Sharing Aggregate Genomic Data. National Human Genome Research Institute (NHGRI). https://www.genome.gov/27566089/workshopon-sharing-aggregate-genomic-data/. Accessed 18 Apr 2019.

4. NOT-OD-17-044: Request for Information on Processes for dbGaP Data Submission, Access, and Management. https://grants.nih.gov/grants/guide/ notice-files/NOT-od-17-044.html. Accessed 18 Apr 2019

5. National Institutes of Health, USA. NOT-OD-19-023: Update to NIH Management of Genomic Summary Results Access. https://grants.nih.gov/ grants/guide/notice-files/NOT-OD-19-023.html. Accessed 27 Jan 2019.

6. National Institutes of Health, USA. Compiled Public Comments on NIH Request for Comments: Proposal to Update Data Management of Genomic Summary Results Under the NIH Genomic Data Sharing Policy. Notice Number NOT-OD-17-110. Compiled Public Comments on NIH Request for Comments: Proposal to Update Data Management of Genomic Summary Results Under the NIH Genomic Data Sharing Policy. Notice Number NOTOD-17-110. https://osp.od.nih.gov/wp-content/uploads/RFC_Compiled_ Report_Final.pdf. Accessed 18 Apr 2019

7. Workshop on Establishing a Central Resource of Data from Genome Sequencing Projects. National Human Genome Research Institute (NHGRI). https://www.genome.gov/27552142/workshop-on-establishing-a-centralresource-of-data-from-genome-sequencing-projects/. Accessed 18 Apr 2019.

8. Retshabile G, Mlotshwa BC, Williams L, Mwesigwa S, Mboowa G, Huang Z, et al. Whole-exome sequencing reveals Uncaptured variation and distinct ancestry in the southern African population of Botswana. Am J Hum Genet. 2018;102:731-43.

9. Uren C, Kim M, Martin AR, Bobo D, Gignoux CR, van Helden PD, et al. Fine-scale human population structure in southern Africa reflects Ecogeographic boundaries. Genetics. 2016;204:303-14.

10. Legal Notes. After Havasupai litigation, Native Americans wary of genetic research. American Journal of Medical Genetics Part A. 2010;152A:fm ix-fm ix.

11. Sterling RL. Genetic research among the Havasupai: a cautionary tale. AMA J Ethics. 2011;13:113-7.

12. Schroeder D, Cook J, Hirsch F, Fenet S, Muthuswamy V. Ethics Dumping: Case Studies from North-South Research Collaborations. Springer International Publishing; 2017.

13. Schuster SC, Miller W, Ratan A, Tomsho LP, Giardine B, Kasson LR, et al, Complete Khoisan and bantu genomes from southern Africa. Nature. 2010; 463:943-7.

14. Kowal EE. Genetics and indigenous communities: ethical issues. In: International Encyclopedia of the Social \& Behavioral Sciences. Elsevier 2015. p. 962-8. https://doi.org/10.1016/B978-0-08-097086-8.82058-9.

15. Neel JV, Salzano FM, Junqueira PC, Keiter F, Maybury-Lewis D. Studies on the Xavante Indians of the Brazilian Mato Grosso. Am J Hum Genet. 1964;16:52-140.
16. Brazil tribe gets back blood samples. 2015. https://www.bbc.com/news/ world-latin-america-32178286.

17. Callaway E. Aboriginal genome analysis comes to grips with ethics. Nature. 2011:477:522-3.

18. Claw KG, Anderson MZ, Begay RL, Tsosie KS, Fox K, Garrison NA. A framework for enhancing ethical genomic research with indigenous communities. Nat Commun. 2018:9:2957.

19. Ilorah R. Ethnic bias, favouritism and development in Africa. Dev South Afr 2009:26:695-707.

20. Charlton L. White Supremacy, Genetics and Dr. James Watson. The New York Times. 2019. https://www.nytimes.com/2019/01/05/us/james-watsonracism-pbs.html.

21. Harmon A. James Watson had a chance to salvage his reputation on race. The New York Times: He Made Things Worse; 2019. https://www.nytimes. com/2019/01/01/science/watson-dna-genetics-race.html.

22. Global Alliance for Genomics and Health. GENOMICS. A federated ecosystem for sharing genomic, clinical data. Science. 2016;352:1278-80.

23. Beacon Network. https://beacon-network.org/\#/. Accessed 2 May 2019.

24. Mulder NJ, Adebiyi E, Alami R, Benkahla A, Brandful J, Doumbia S, et al. H3ABioNet, a sustainable pan-African bioinformatics network for human heredity and health in Africa. Genome Res. 2016;26:271-7.

25. The H3Africa Informatics Network. H3ABioNet. https://www.h3abionet.org/. Accessed 2 May 2019

26. Balding DJ, Nichols RA. A method for quantifying differentiation between populations at multi-allelic loci and its implications for investigating identity and paternity. Genetica. 1995:96:3-12

27. Bhatia G, Patterson N, Sankararaman S, Price AL. Estimating and interpreting FST: the impact of rare variants. Genome Res. 2013;23:1514-21.

28. Lappalainen I, Almeida-King J, Kumanduri V, Senf A, Spalding JD, ur-Rehman $S$, et al. The European Genome-phenome Archive of human data consented for biomedical research. Nat Genet. 2015:47:692-5.

\section{Publisher's Note}

Springer Nature remains neutral with regard to jurisdictional claims in published maps and institutional affiliations.
Ready to submit your research? Choose BMC and benefit from:

- fast, convenient online submission

- thorough peer review by experienced researchers in your field

- rapid publication on acceptance

- support for research data, including large and complex data types

- gold Open Access which fosters wider collaboration and increased citations

- maximum visibility for your research: over $100 \mathrm{M}$ website views per year

At $\mathrm{BMC}$, research is always in progress.

Learn more biomedcentral.com/submissions 